\title{
Airborne Aspergillus at some rural areas adjoining to Raipur city (C.G.) India
}

\author{
${ }^{*}$ Ritu Kunjam ${ }^{1}$, V.K. Kanungo and S.K. Jadhav
}

\author{
${ }^{1}$ Department of Botany, \\ Govt.Nagarjuna P.G. College of Science, \\ RAIPUR (C.G.) INDIA \\ Department of Biotechnology, \\ Pandit Ravishankar Shukla University. \\ RAIPUR (C.G.) INDIA \\ ${ }^{*}$ Corresponjding Author \\ E-mail: ritukunjam21@gmail.com
}

Received : 15.09.2020; Accepted : 01.11 .2020

\begin{abstract}
Increased urbanization and industrialization in recent time has made a significant impact on air quality of the area. The atmosphere is rich in propagule of different fungal species. The investigation on airborne Aspergillus contribution was conducted in Periphery of Raipur city from February, 2018 to March, 2019 with the help of gravity petriplate containing PDA (Potato Dextrose Agar) medium. In this study, total 11 species of Aspergillus were recorded. The percentage frequency and percentage contribution of different Aspergillus species were different in different seasons. Aspergillus niger was most frequent throughout the year followed by Aspergillus fumigatus, $A$. flavus, and $A$. nidulans etc. While Aspergillus clavatus, and $A$. versicolor, $A$. aculeatus were the least frequent species. The result indicated the highest percentage contribution of Aspergillus niger (43.29 percent) followed by $A$. fumigatus (9.02percent), $A$. flavus ( 8.42 percent) while $A$. clavatus ( 0.21 percent). The objective of the studies was to determine a seasonal variation in concentrations of Aspergillus on the basis of meteorological parameters.
\end{abstract}

KEY WORDS : Airborne, Aspergillus, Raipur city, Rural Area.

\section{Introduction}

Fungal spores constitute a major component of air-spora. Qualitative and quantitative variations depend on the meterological factors and geographical conditions. Fungal spores that are transported by air currents cause many plant diseases and knowledge of their periodicity is of great value in terms of predicting plant epidemics. Aspergillus is a universal fungus. The great majority of species are saprophytes, commonly or occasionally found in soil, decaying vegetation, seeds and grains. The aim of present work was to analyse the behaviour of Aspergillus spore type at some rural areas adjoining to Raipur city and to study the relationship between the fungal spore levels and the main environmental factors.

\section{Materials and Methods}

In present study, four different sites were selected for sampling Aeromycoflora Chandanidih, Zora, Boriakala, Dhaneli, Baronda, and Dumartarai. The study was carried out during March 2018 to February 2019. The culture plate exposure method was adopted for trapping the mycoflora. PDA (Potato, Dextrose and Agar) was used as culture medium. $10 \mathrm{ml}$ of sterilized PDA medium was aseptically poured in petriplates and allowed to solidify. Five petriplates containing potato dextrose agar (PDA) medium were exposed in the air for 5-10 minutes at 1 meter above the ground level at the above-mentioned sites. The study was conducted at interval of 15 days in every month. The exposed petridishes were sealed and brought to the laboratory and incubated for 3 to 6 days at $26 \pm 1^{\circ} \mathrm{C}$. After incubation fungal colonies were counted, isolated and identified with the help of literature ${ }^{1,2}$. The results were recorded separately for different sites / season. Percentage frequency and percentage contribution of the fungal flora will be calculated with the help of following formula 8 : -

$\%$ Contribution $=$ Total No. of colonies of species in all the observations taken together / Total no. of colonies of all species $X 100$

\section{Result and Discussion}

The investigation of airborne Aspergillus concentration was conducted at some rural areas of adjoining to Raipur city. 2019. During present study 377 fungal colonies of 11 species of Aspergillus were recorded (Table -1). 


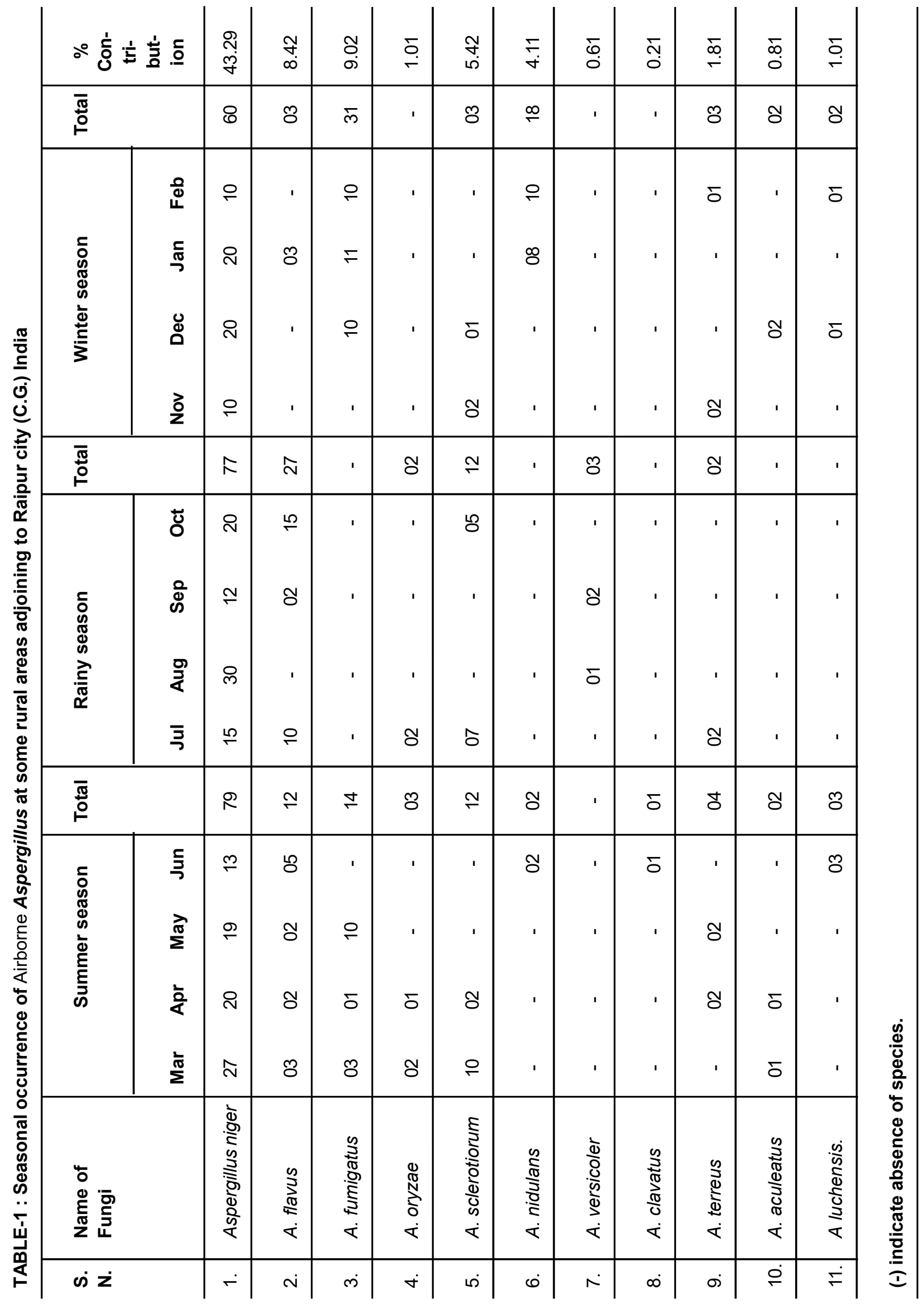


The percentage frequency and percentage contribution of different Aspergillus species were different in different seasons. Aspergillus niger was most frequent throughout the year followed by Aspergillus fumigatus, Aspergillus flavus, Aspergillus sclerotiorum and Aspergillus nidulans etc. Aspergillus clavatus, Aspergillus versicolor, and Aspergillus aculeatus were the least frequent species. The result has indicated the highest percentage contribution of Aspergillus niger (43.29\%) followed by Aspergillus fumigatus (9.02\%), Aspergillus flavus $(8.42 \%)$ while Aspergillus clavatus $(0.21 \%)$ and Aspergillus versicolor $(0.61 \%)$ made the lowest contribution to the total species.

This is partly reported that Aspergillus niger and Aspergillus fumigatus were some of the most frequent fungi on the leaf surface mycoflora of Oscimum sanctum ${ }^{7}$. Similar observations were reported that $A$ spergillus were the most dominant saprophytes in the atmosphere ${ }^{12}$. The species of Aspergillus contributed highest to the total aerospora in Costal belt of Orissa 5 . Aspergillus species were predominant component of the outdoor aerospora of Kuwait ${ }^{3}$. Maximum contribution of Aspergillus was also observed from different places like Aurangabad ${ }^{9}$, Kanpur $^{6}$ and Raipur ${ }^{4,8,10}$. Aspergillus niger was most dominant fungal spores from slum area of Raipur ${ }^{11}$. Meteorological factors, such as local agricultural activities, biological sources should be considered in future studies to fully understand the behaviour of Aspergillus.

\section{Conclusion}

The initial study over the year gives qualitative and quantitative data on the airborne Aspergillus at some rural areas adjoining to Raipur city. A total of 11 species of Aspergillus were isolated and identified during the year and their occurrence with seasonal variation was noted. Aspergillus niger was dominant fungal species found all the season during the study period.

\section{References}

1. Barnett HL, Illustrated genera of Imperfect fungi (Mins Burgess Pub. C.o.) 1969.

2. Ellis MB. Diatomaceous Hyphomycetes. Kew. England Common Wealth Mycological Institute 1971.

3. Khan ZU, Khan MA, Chandy R, Sharma PN. Aspergillus and other moulds in air of Kuwait. Mycopathologia. 1999; 146(1):25-32.

4. Khan S, Kanungo VK, Jadhav SK. Variation in aeromycoflora of Raipur city with special reference to allergic diseases. Indian Journal of Applied and Pure Biology. 2016; 31 (2):131-142.

5. Panda T, Panda B, Mishra N. Seasonal Incidence of Air Borne Fungi in Costal Belt of Orissa. J Hum Ecol. 2009; 26 (3): 205-207.

6. Rajan BS, Nigam S, Shukla RK. A study of atmospheric fungal flora at Kanpur. Proc.Indian Acad.Sci.1952; 35(B): 33-37.

7. Sharma K. Studies of aeromycoflora in relation to leaf surface mycoflora of Ocimum sanctum L., Ph.D. Thesis, Pt. Ravishankar Shukla University, Raipur. 2001.

8. Singh NB. Studies of aeromycoflora in relation to leaf surface mycoflora of Mentha arvensis Linn.Ph.D. Thesis Pt. Ravishankar Shukla University, Raipur (C.G.). 2006.

9. Tilak ST, Srinivasulu BV. Airspora of Aurangabad. Ind. J. Microbial. 1967; 7: 167 - 170.

10. Tiwari KL, Jadhav SK. Aeromycological studies of chemistry lab of Govt. College, Balodabazar, Raipur (C.G.) India. Ecol. Enb. \& Cons. 2004; 10 (3): 383 - 385.

11. Tiwari KL, Jadhav SK, Kunjam SR. Aeromycoflora of slum area of Raipur (C.G.), Ad. Plant Sci. 2006; 19: 387390.

12. Uddin N. Airspora studies over a rice (high yielding variety) field in rabi season in the state of West Bengal, India. Aerobiologia. 2004; 20(2):127-134. 